STUDIA ROSSICA POSNANIENSIA, vol. XL, cz. 1: 2015, pp. 125-135. ISBN 978-83-232-2878-3. ISSN 0081-6884.

Adam Mickiewicz University Press, Poznań

\title{
ЗАМЕТКИ О ГРАММАТИКЕ ОБОБЩЕНИЙ (НА МАТЕРИАЛЕ АФОРИЗМОВ)
}

\author{
ON THE GRAMMAR OF GENERALIZATIONS \\ (BASED ON THE EXAMPLE OF APHORISMS)
}

\author{
АГНЕШКА ГАШ
}

ABSTRACT. Generalization does not only catch the interest of philosophers, logicians and psychologists but also that of linguists. This is mainly because generalization, which results from human intellectual activity, is reflected in language and therefore also in texts that are created by human beings. Aphorisms are by nature adjusted to expressing generalized information and are considered the most widespread form of expressing the so-called generic language register, as defined by G.A. Zolotova. The main criteria for assigning a given text to this register are a generalized subject and a timeless predicate. By taking into account the above criteria for assigning texts to this register, sentence analysis reveals the most essential features of aphoristic generalizations, which can be shown on the subject-predicate-object axis, including a qualitative, quantitative and space-time description. Bearing in mind the most important structural and semantic characteristics of aphorisms, one may arrive at the conclusion that they reflect features that are typical of sentences with the so-called generalized referential status.

Agnieszka Gasz, Uniwersytet Śląski, Katowice - Polska.

Обобщенность, как заметил Ф. де Соссюр, имеет специфику своего проявления в любом языке. Настоящий очерк имеет целью проследить специфику ее выражения в русском языке на материале текстов афоризмов ${ }^{1}$. Механизмы обобщения (генерализации) тесно связаны с про-

${ }_{1}$ Мысль де Соссюра на русском языке почерпнута из работы Г.Н. К о н д р а т ь е в о й, Обобщенность как структурно-семантическая категория $b$ современном русском языке. Автореферат диссертации на соискание ученой степени доктора филологических наук, Москва 1994, с. 5. Материал для анализа отобран из русских и польских сборников афоризмов. В данной работе внимание сосредоточивается на выявлении грамматической природы механизмов обобщений. Примеры приводятся на русском языке, хотя часть из них - это тексты переводные, в частности из польского, французского, латинского языков. Вопросы перевода в рамках настоящего анализа не рассматриваются. Важнейшие источники на русском языке: К.В. Д у ш е н к о, 2000 лучших афоризмов, Москва 2000; его же, Мастера афоризма, Москва 2001; его же, Большая книга афоризмов, Москва 2005; С.Е. Л е ц, Почти все, пер. с польск. В. Россельса, Е. Фридмана, Москва 2008. Важнейшие источники на польском языке: J. G 1 e n s k, Wspótczesna aforystyka polska, Łódź 1986; S.J. L e c, Myśli nieuczesane, Kraków 
цессом формирования общих понятий. Уместно при этом отметить, что лат. выражение generalis обозначает 'всеобщий'. Механизмы эти находят свое выражение в виде обобщенных суждений.

Как видно, в русском языке существует два синонимических понятия: генерализация и обобщение (в литературе они употребляются попеременно). По Большому толковому словарю русского языка под редакцией С.А. Кузнецова, генерализация понимается как 'логический переход от частного к общему, подчинение частных явлений общему принципу; обобщение 2 . В свою очередь, исконно русское слово обобщение толкуется в словаре как 'общий вывод, общее положение, основанное на получении отдельных фактов, явлений’3.

Феномен генерализации испокон веков занимает не только философов и логиков. В наше время к нему испытывают особый интерес прежде всего социологи и психологи, но суть механизма обобщения находится также в центре внимания лингвистов. Несмотря на некоторые разницы в подходе к изучению данного вопроса, вытекающие прежде всего из научных целей, которые ставит соответственно логика, философия или психология, кажется, что связующим звеном между вышеотмеченными научными дисциплинами является именно язык.

Человек воспринимает действительность в виде контрастных противопоставлений: каждый - все - никто, единичность - собирательность. С одной стороны, мы воспринимаем деталь, единицу, с другой - множество. На одном полюсе находится константность, а на другом - переменность. На основе отмеченных оппозиций у нас формируются представления относительно окружающей действительности, систематизируются и классифицируются объекты и явления. Эти представления приобретают форму общих суждений. Предложение, имеющее обобщающий статус, трактует о каком-либо множестве ${ }^{4}$, напр.: Мужчины - это донжуаны. Женщины - это кокетки. Этого рода ментальные операции в большой степени помогают человеку осваиваться с окружающей действительностью, так как мы наблюдаем не только постоянные правила типа: Человек смертен, но также стереотипные упрощения, напр.: Мужчины думают, женщины чувствуют. Суть упрощения состоит в том, чтобы какое-либо явление стало менее сложным и более понят-

1974; L. K u m o r, Pomyślenia, czyli aforyzmy, Warszawa 1979; Z. D o 1 a t k o w s k i, Aforyzmy i uwagi, Warszawa 1998; D.W. M a s ł o w s c y, Księga aforystyki polskiej XXI wieku. Potega myśli, Katowice 2002. Автор русского перевода: П. Червиньский (переведенные примеры обозначаются пометой: *).

2 Большой толковый словарь русского языка, под ред. С.А. Кузнецова, Санкт-Петербург 2008, с. 198.

3 Там же, с. 677.

${ }^{4}$ T. N o w a k, Szkolny stownik wiedzy o języku, Warszawa 2005, c. 179. 
ным, но, как правило, это поверхностный подход к определенному вопросу или проблеме. Таким образом возникают так наз. ложные (неточные) обобщения, которые не поддаются эмпирической верификации (как это имеет место в логике). В разговорной речи люди часто прибегают к обобщениям, которые играют важную роль как своеоразное языковое орудие манипуляции. Это особенно заметно в языке рекламы или политического дискурса, так как в языке политических дебатов или политической пропаганды часто используетя генерализация как прием, позволяющий достичь некоторых целей. Обобщение позволяет распространять, внушать и даже навязывать определенный тип мировоззрения, систему ценностей и т. д. В обыденной коммуникации неоднократно имеем дело с употреблением обобщенного предложения вместо конкретного в референциально-коммуникативном плане, ср.: Почему женщины всегда так переживают?, Почему ты всегда так переживаешь? Таким образом выражается стереотипное, неверифицируемое, обобщение. На основании единичного случая формируется суждение, касающееся класса в целом. Данная стратегия позволяет говорящему избегать каких-либо вопросов - в зависимости от коммуникативной ситуации - неловких, трудных и т. п., а также в значительной степени вытесняет на задний план личное отношение говорящего.

Естественные языки располагают широкой палитрой разного типа средств (лексических, грамматических), способствующих выражению обобщающих суждений на тему объектов и явлений действительности. В новейших лингвистических трактовках наблюдается выразительная тенденщия учитывать этот фактор, т. е. принимается во внимание степень обобщенности выражаемой информации (при классификации предложений и текстов). Типология текстов составляется с учетом тематики и жанра, а также лексико-грамматической специфики текста. Одновременно существует и так наз. функционально-синтаксическая классификация в виде коммуникативных регистров (по Г.А. Золотовой). Основным критерием, решающим о регистровой принадлежности текста, является степень обобщенности или конкретности описываемых в тексте предметов или явлений, что тесно связано с референтными особенностями названий и временной локализированностью предиката 5 .

В классификации коммуникативных регистров речи по Золотовой выделяется генеритивный регистр, позволяющий говорящему формулировать (или цитировать) высказывания высшей ступени обобщения. Генеритивные высказывания чаще всего облекаются в форму умозаключений, афоризмов, сентенщий, пословиц. Коммуникативные ин-

${ }^{5}$ Ср.: М.Ю. С и д о р о в а, Коммуникативные типы текста, [в:] ее же, Современный русский язык. Синтаксис. Сборник упражнений, Москва 1998, с. 8-9. 
тенции говорящего по отношению к внеязыковой действительности в генеритивном регистре речи сводятся к представлению обобщенной информации, соотнеся ее с жизненным опытом и универсальным знанием. В качестве субъектов предложения выступают генерализованные множества, классы существ, предметов, а также природные, социальные процессы как явления, понятияб.

На основании сказанного легко уловить заметную параллель: афоризм как краткая литературная форма и высказывания обобщающего характера. Афоризм - это микротекст, от природы приспособленный к выражению обобщенной информации, а также (наряду с пословицей) наиболее типичная форма выражения высказываний генеритивного регистра речи. Вопрос о дефиниции афоризма до сих пор остается открытым, главным образом из-за перекрещивания объемов понятий терминов родственных жанров (сентенция, максима), эволюционных изменений, а также из-за межъязыковых терминологических различий ${ }^{7}$. В литературе можно найти много толкований термина афоризм ${ }^{8}$. В большинстве из них обнаруживается одна общая черта: обобщенность (ср.: наиболее частотные определения: обобщающий, обобщенный, содержащий обобщение, полученный обобщением). Учитывая данные сведения, можно считать обобщенность одним из важнейших жанровых показателей афоризма. Таким образом, афоризм как своеобразное литературно-языковое явление может функционировать в качестве носителя обобщенной информации ${ }^{9}$. Однако надо отдавать себе отчет в том, что не каждый афоризм удовлетворяет данному критерию. Это видно при

${ }^{6}$ Г.А. 3 о л о т о в а, Н.К. О н и п е н к о, М.Ю. С и д о р о в а, Коммуникативная грамматика русского языка, Москва 2004, с. 30-33.

7 Более подробно эти сложные вопросы обсуждаются в статье А. Г а ш, Несколько замечаний о двойной природе афоризма (лингвистический подход), [в:] Коммуникативные аспеты предложения и текста, под ред. А. Чапиги, 3. Чапиги, Жешув 2009, c. 27-35.

8 Ср. словарные статьи: С.И. О ж е г о в, Н.Ю. Ш в е д о в а, Толковый словарь русского языка, Москва 1999, с. 32; Большой толковый словарь..., указ. соч., с. 52; А.П. Г о р к и н, Новый энциклопедический словарь, Москва 1999, с. 59. Ср. также: Н.Т. Ф е д о р е н к о, Л.И. С о к о л ь с к а я, Афористика, Москва 1990, с. 181-182.

${ }^{9}$ В рамках настоящей работы афоризм рассматривается как самостоятельный носитель обобщенной информации. Больше на тему специфики афоризма как текста с двойной природой см. работы: А. G a s z, On the dual nature of the aphorism (a linguistic approach), [в:] Perspectives on Slavistics. Book of Abstracts, ed. B. Brehmer, S. Schadat, B. Trawinski, A. Werberger, Hamburg 2008, c. 27-28; А. Г а ш, О феномене „текста В тексте" (лингвистический подход к изучению афоризма), [в:] Материалы 51-й международной научной конферениии Даугавпилсского университета, vol. 1, под ред. Д. Олехновича, Даугавпилс 2008, с. 140-145. 
сравнении афористических высказываний: Я снова был в Вене. Как же я изменился! (С.Е. Лец)*, Человек - гибрид обезьяны и времени. (С.Е. Лец)*.

В качестве примеров приводятся тексты С.Е. Леца (1909-1966) - известнейшего польского афориста ${ }^{10}$. Итак, первый афоризм представляет собой пример конкретного предложения, референциальный статус которого можно определить как определенный. Об этом свидетельствует личное местоимение $я$, указывающее на лицо говорящего. Из контекста заключаем, что речь идет о ком-то определенном (можно здесь также заметить автобиографический намек) $)^{11}$. Второй афоризм имеет совсем другой характер. Его содержание универсальное.

Анализ собранного материала имеет целью проиллюстрировать наиболее характерные языковые стратегии с учетом важнейших грамматических особенностей, благодаря которым афоризмы получают обобщенный смысл и универсальное прочтение.

1. Собственные имена в обобщающем контекте афоризмов. Своеобразную роль в порождении обобщенного прочтения афоризмов играют собственные имена ${ }^{12}$. В афористике преобладают антропонимы (названия мифологических, библейских персонажей, литературных героев, общеизвестных лиц: философов, ученых, изобретателей и т. п.), а также топонимы (географические названия континентов, стран, городов и рек). В текстах афоризмов часто имеем дело с антономазией, т. е. заменой нарицательного имени собственным, напр.: Еъа вместо женщина, ср.: Мужчина - создание полигамное: желает одновременно Еву u викторию (А. Маевски) ${ }^{*}$. Процесс апеллятивизации связан с расширением лексической семантики слова, т. е. под влиянием генерализации (расширения объема названия) слово не обозначает уже некоторый индивид, а класс однородных предметов. Слово, раныше обозначающее единичный объект, приобретает черты, типичные для нарицательных имен. В связи с этим у собственных имен наблюдается тенденция

10 Е. Ф р и д м а н так пишет о творчестве Леца:

Не будь он поэтом, притом таким поэтом, вряд ли он поднялся бы до высот образного обобщения, позволяющего называть его еще и философом нашей эпохи. Его рубленые фразы составлены из тех же слов, которыми ежедневно пользуемся мы. В них заключены идеи, на первый взгляд, наивные, ловко уводящие нас в исторические подвалы. Но подтекст в них глубоко современный, даже больше - всевременный,

см.: Очерк о жизни и творчестве С.Е. Лец̧а, [в:] С.Е. Л е ц, указ. соч., с. 5-6.

11 Фридман замечает, что Леца, одинокого скептика, обвиняли в индивидуализме, поскольку в пятидесятые годы проявлять личность автору не полагалось, ср.: там же, с. 7 .

12 A. G a s z, Antroponimy w kontekście uogólniającym (na przykładzie aforyzmów w języku rosyjskim i polskim), [в:] Имя и слово (проблемы семантико-прагматического взаимодействия в славянских языках), ч. 2, под ред. В.И. Сенкевича, Брест 2007, с. 152-157. 
к образованию форм множественного числа, ср.: Многие из тех, кто считает себя донжуанами, всего лишь фавны (М. Эбнер-Эшенбах).

2. Нарицательные имена и обобщенный референциальный статус. В афоризмах употребляются нарицательные существительные, которые в зависимости от контекста получают обобщенный или определенный референциальный статус. Языковые единицы, содержащие обобщающий компонент, характеризует неконкретность, иногда неизвестность лица или предмета. Количественный диапазон референта рассматривается в пределах от „несколько до всеохватного множества”, т. е. до бесконечности, напр.: От радости собака виляет хвостом. Для этого нужны радость и хвост (С.Е. Лец). Отметим также, что для имен существительных, употребляемых в родовом и типизирующем значениях, характерна нейтрализация категории числа. В подобных случаях лингвисты говорят о так наз. единственном и множественном родовом (употребление соответственно: формы единственного или множественного числа имени для обозначения данного класса или рода предметов $^{13}$, ср.: собака виляет = собаки виляют). Множественное число, представляющее класс как множество, более конкретно; единственное число, представляющее класс как целое, более абстрактно. Как правило, форма единственного может заменяться формой множественного числа, но в некоторых контекстах такая замена не допускается. При некоторых предикатах употребляется только форма обобщенного множественного числа (тотальное, нераспределенное понимание), напр.: Динозабры вымерли, поскольку разбивались неправильно: избыток панциря и недостаток мозга (М. Добросельски)*.

Инвентарь лексем, употребляемых в качестве обобщенного личного или неличного субъекта-объекта, весьма разнообразен. Нарицательные существительные - это обобщенные названия однородных предметов: лиц (человек), животных (собака), явлений природы и веществ (вода, песчинка), а также абстрактных понятий (добро); названия, обозначающие совокупность одинаковых (или подобных) отдельных предметов в отвлечении от этих последних (человечество), названия опредмеченных, субстантивированных действий, состояний, процессов (лечение).

Таким образом, выражению обобщенных суждений способствуют слова, которые относятся (отсылают) ко многим лицам, предметам, явлениям. В текстах афоризмов генерализующее референциальное употребление может касаться любого пункта семантической структуры предложения.

3. Обобщающие местоимения в афоризмах. Типичным показателем семантики обобщенности являются субстантивированные обоб-

${ }^{13}$ О.С. А х м а н о в а, Словарь лингъистических терминов, Москва 2004, с. 147. 
щенно-распределительные местоимения (всякий, ююбой, каждый- все). Их объединяет сема „лицо” 14 . В предложении данные местоимения очень часто сочетаются с общими названиями типа человек, женщина и тогда они выполняют определительную функцию, напр.: Каждый человек $b$ отдельности смертен, человечество же в иелом бессмертно (Апулей). Одной из форм обобщительного местоимения весь считается также местоимение $b c \ddot{e}$, для которого - в свою очередь - характерна сема „предмет”. Предметное выражение-тотализатор всё и личное все обозначают соответственно: совокупное множество предметов и лиц. Данные текстовые показатели коллективной генерализации позволяют обобщать глобально, т. е. выражать целостную характеристику класса, напр.: Все равны перед лицом смерти и ... смеха (3. Долятковски)*.

Существенную роль в порождении обобщенного смысла афористических суждений играют отрицательные местоимения, ср.: Никто не обнимет необъятного (К. Прутков), Ничто так не мешает видеть, как точка зрения (Дон-Аминадо), а также местоимение некоторые, трактующее о части множества, напр.: Некоторые так любят пафос, что согласны читать с подъемом любой текст (С.Е. Лец)*.

Очень характерной стратегией генерализации в афористике является сочетание в рамках одного предложения нескольких обобщающих операторов как однородных, так и неоднородных (т. е. с противоположным значением). Возможно несколько вариантов и комбинаций, ср.: Если бы все знали, что все говорят обо всех, то все не разговаривали бы со всеми (Г. Оното); Все жалуются на свою память, но никто не жалуется на свой разум (Ф. де Ларошфуко). Анализируемые местоимения вносят в афористическое суждение высокую дозу абстрактности. Иногда предложение как будто стоит на грани информативности, но с помощью комбинирования разных типов обобщающих операторов афористы достигают интересного стилистического эффекта (получаются контрасты, выявляются противоречия, парадоксы и т. п.).

Стереотипные афористические обобщения, касающиеся определенного множества лиц, предметов или явлений, очень часто выражаются также путем приблизительности (аппроксимации), языковым показателем которой является лексема почти, напр.: Почти все начальники превышают свои права, обязанности - почти никто (В. Георгиев). Такую же функцию выполняют слова и выражения, позволяющие формулировать суждения на тему части множества типа: больщинство, половина, большая часть, часть, меньшинство, ср.: Большинство людей не

${ }^{14}$ Г.Н. К о н д р а т ь е в а, Обобщенность как структурно-семантическая категория в современном русском языке. Автореф. дисс. ...д-ра филол. наук, Москва 1994, c. 20 . 
имеет жизненной квалификации (Е. Иваницки)*, Меньшинство Всегда не право - вначале (Г. Прокноу). Благодаря употреблению приведенных лексем выражается партитивная характеристика множества. Такая манера обобщать приблизительно в повседневной речи является, так сказать, более „безопасной”, так как дает нам возможность высказать обобщенную мысль, вытекающую из наблюдений действительности, но одновременно допускается существование исключений от сформулированного общего суждения или правила. Лингвисты указывают также на семантическое родство выражений, трактующих о части множества, ср.: часть ююдей (существительное) и некоторые ююди (прилагательное) $)^{15}$.

4. Семантика обобщенной качественности. В качественном отношении для генерализующего прочтения смысла афористического предложения особенно важна функция суперлативных определений (без отнесения к конкретному объекту) ${ }^{16}$, напр.: Самый глупый человек на свете испытывает те же чувства, что и самый умный (Ф. Честерфилд). Стоит также отметить интересное явление субстантивного (неизосемического) употребления качественных прилагательных в обобщенном значении, ср.: Только мертвый для жизни готов (Д. Хендрикс). Для выражения обобщения афористы часто прибегают к употреблению сравнительных конструкций, в которых - в свою очередь - выступают формы сравнительной степени: Чем меньще граждане, тем больще кажется империя (С.Е. Лец)*. Обобщающая функция качественных, относительных и притяжательных прилагательных состоит также в выделении различных видов и типов объектов - это видовые определения, напр.: Мысли бывают золотые, поверхностные и чужие (Р. Гожельски)*.

5. Семантика генерализованного количества. Генерализирующая роль числительных в афоризмах сводится к точному, а также приблизительному выражению количества лиц, предметов или явлений. Числительные, так же, как и прилагательные, проявляют способность к косвенной номинации, ср.: один 'человек', напр.: Один пишет, потому

${ }^{15}$ A. B o g u sł a w s k i , O jezzyku i jego analizie, [в:] его же, Semantyczne pojęcie liczebnika i jego morfologia w języku rosyjskim, Wrocław-Warszawa-Kraków 1966, c. 32-33.

${ }^{16} \mathrm{O}$ семантике суперлатива см.: Д.М. К а л а ш н и к, Превосходная степень и семантика оценки. О разграничении суперлатива и элатива, [в:] Теория функциональной грамматики. Качественность. Количественность, под ред. А.В. Бондарко, Санкт-Петербург 1996, с. 145. Вопрос генерализующего употребления форм суперлатива в текстах афоризмов рассматривается также в статье: A. G a s z, Kilka uwag o uogólniającym użyciu form stopnia najwyższego przymiotnika w tekstach aforyzmów (na materiale rosyjskim i polskim), [в:] Gramatyka a tekst, pod red. H. Fontańskiego, J. Lubochy-Kruglik, Katowice 2008, c. 121-130. 
что видит, другой - потому что слышит (К. Краус). Они позволяют также выделять разные типы объектов: Есть два вида дураков: одни думают, что они умные, другие уверены, что так оно и есть (Я. Джангирова).

В обобщающих контекстах афоризмов кроме количественных, собирательных, порядковых и дробных числительных, а также неизосемических единиц ${ }^{18}$, выражающих значение количества (это, как правило, языковые средства усиливания количества лиц и предметов типа: многие, тысячи, трилионы, масса, множество и т. п.), отмечается употребление единиц измерения: массы, объема, длины и расстояния и др., ср.: Многие ююди читают иишь для того, чтобы иметь право не думать (Г. Лихтенберг) и Мерой человека яВляется метр (С.Е. Лец)*.

6. Категория времени и наклонения глагола при обобщении. Общереферентный статус предиката достигается главным образом благодаря употреблению итеративных форм настоящего времени ${ }^{19}$, так наз. praesens gnomicum (презенс генералис), напр.: Человек рождается, живет, умирает, а дважды два постоянно четыре (Х. Ягодзиньски)*. Универсальное значение могут выражать формы как прошедшего, так и будущего времени, ср.: гномический аорист: Человек стал философом, когда сказал "я существую" (Л. Кумор)*, fиtитит gпотісит: Любящая женщзина Все простит, но ничего не забудет (Х. Джербан).

В афористике особую позицию занимают экзистенциальные глаголы типа быть (итеративное бывать), существовать, иметься, благодаря которым реализуются экзистенциальные обобщения ${ }^{20}$, напр.: Есть дba

$18 \mathrm{O}$ категориальных значениях частей речи (изосемических и неизосемических) см.: Г.А. 3 о л о т о в а, Н.К. О н и п е н к о, М.Ю. С и д о р о в а, указ. соч., c. $108-110$.

${ }^{19} \mathrm{O}$ семантике обобщенного употребления форм настоящего времени см. в частности: J. L у о n s, Czasy gramatyczne $i$ deiktyczne odniesienia czasowe, [в:] его же, Semantyka, przeł. A. Weinsberg, t. 2, Warszawa 1989, c. 279-284; M. G r o c h o w s k i, Znaczenie polskiego czasownika: aktualne, potencjalne, habitualne, uniwersalne - w świetle kategorialnego znaczenia form czasu teraźniejszego, "Studia Semiotyczne” 1972, vol. III, c. 163; E. K o s c h m i e d e r, Fakty bez wartości miejscowej w czasie, [в:] его же, Nauka o aspektach czasownika polskiego w zarysie. Próba syntezy, Wilno 1934, c. 85, 92; А.В. Б о н д а р к о, Типы временной локализованности, [в]: его же, Теория функииональной грамматики. Введение. Аспектуальность. Временная локализованность. Таксис, Ленинград 1987, с. 227-228; A. G a s z, Uogólnienia w aspekcie kategorii gramatycznych czasownika (na materiale rosyjskich tekstów aforystycznych w konfrontacji z językiem polskim), "Studia Rusycystyczne Akademii Świętokrzyskiej" 2005, vol. XV, c. 49-60.

20 Шире на тему экзистенциальных обобщений: J. L u b o c h a - K r u g l i k, Rosyjskie zdania egzystencjalne w konfrontacji z polskimi, Katowice 2001, c. 31-32; A. G a s z, Predykaty iteratywne w tekstach aforystycznych (na materiale jezyka rosyjskiego i polskiego), [в:] Gramatyka a tekst, pod red. H. Fontańskiego, J. Lubochy-Kruglik, Katowice 2007, c. $127-144$. 
типа мужчин: одни молодые, симпатичные с будущим; другие подумывают о женитьбе („Пшекруй”).

В аспекте выражения всевременности существенную роль играют также повелительные формы (панхронический императив) в соответствующих прагматических функциях, как универсальные поучения, приказы, предостережения, советы, желания ${ }^{21}$, напр.: Не пожелай жены ближнего твоего всуе (Х. Сенкевич), Уступайте место дамам в вамем сердие! (С.Е. Лец)*.

7. Наречные показатели всевременности. Обобщающее значение предиката особым образом подчеркивают темпоральные и локативные показатели универсальности 22 - наречия типа всегда, никогда, везде, нигде, напр.: Круглые числа всегда лгут (С. Джонсон), Искусство никогда не умирает (Петроний Арбитр Гай), Кто везде, тот нигде (Сенека Луций Анней). Кроме отмеченной антонимической пары наречий, в афористике встречается целый ряд временных показателей неточных (приблизительных) обобщений, напр.: иногда, время от времени, как правило, чаще всего, нередко, часто, редко и т. п. Ценными в этом отношении (особенно если речь идет о выражении сравнения) являются также лексемы с темпоральным значением типа: раньше, прежде - сейчас, теперь и многие другие.

8. Обобщенные синтаксические модели в афоризмах. Афористические суждения чаще всего облекаются в форму сжатых дефиниций, силлогизмов, конструкций сравнительного и условного характера. Учитывая референциальную характеристику, афоризмы реализуют

21 Больше на тему панхронического употребления повелительных форм глагола см., напр.: I. D u l e w i c z o w a, Z badań nad kategoria osoby w języku polskim i rosyjskim, „Studia z Filologii Polskiej i Słowiańskiej” 1978, vol. XVII; Z. T o p o 1 i ń s k a, O kategoriach gramatycznych polskiego imperatiwu, "Językoznawstwo Polskie" 1966, vol. LXVI.; A. G a s z, Uniwersalizm aforyzmu w aspekcie semantyki imperatywnego trybu sktadniowego (na materiale jezyka rosyjskiego w konfrontacji z jezykiem polskim), [в:] Stowianie w Europie. Historia. Kultura. Jezzyk, pod red. K. Pietrzyckiej-Bohosiewicz, A. Wawrzyńczaka, W. Marinczenki, vol. II, Kraków 2005, c. 291-301.

22 O наречных показателях универсальности см.: R. G r z e g o r c z y k o w a, Zaimki uogólniające a mechanizmy tworzenia zdań ogólnych, „Prilozi” 1987, vol. XII, c. 137; R. G r z e g o r c z y k o w a, Określniki ilościowe czasownika (przystówki kwantyfikujące), [в:] еe же, Funkcje składniowe polskich przystówków, Wrocław-Warszawa-Kraków-Gdańsk 1975, с. 52; Л.Д. Л е б е д е в а, Пространственные и временные указания 6 общереферентных высказываниях, „Известия АН СССР. Серия лит. и яз.” 1984, vol. 43, № 4, с. 308.; E.V.P a d u c z e w a, Zaimki uniwersalne. Znaczenie „vsegda/zawsze”, [в:] ее же, Wypowiedź i jej odniesienie do rzeczywistości, przeł. Z. Kozłowska, Warszawa 1992, c. 331; A. G a s z, Uogólniająca funkcja jednostek "wszędzie", "nigdzie” w tekstach aforystycznych (na materiale języka rosyjskiego i polskiego), [в:] Świat Stowian w języku i kulturze, vol. VII, pod red. E. Komorowskiej, D. Dziadosz, Szczecin 2006, c. 67-71. 
главным образом четыре модели предложения с обобщенным референциальным статусом: дистрибутивые, коллективные, родовые, типизирующие (по Р. Гжегорчиковой) - в зависимости от именной группы, реализующей соответствующую модель. Эти группы - в свою очередь - наблюдаются в рамках простого предложения, но они могут распространяться в более сложные структуры (сложносочиненные и сложноподчиненные). В случае если всевременному предикату не сопутствует обобщенный субъект, имеем дело с обобщенно-личной модификацией субъекта в трех разновидностях: пословичного, оценочного и повествовательного типа (по Г.А. Золотовой). В афористике чаще всего встречаются примеры предложений пословичного типа ${ }^{23}$, где главный член выражается формой 2 л. ед. ч., а также формой 3 л. мн. ч., ср.: В чужой постели Всегда хуже спишь (Колетте), Одаренному коню в зубы не смотрят (Л. Лагин).

9. Заключение. Категория обобщенности - самая абстрактная. Принимая во внимание характер обобщения, в афористике можно отметить генерализации точного характера, особенно в случае экзистенциально-философских суждений, касающихся человека, постоянных явлений и закономерностей, наблюдаемых в природе и в окружающей действительности. В чистом виде данная разновидность генерализации встречается довольно редко, поэтому в афористике явно преобладают стереотипные обобщения, реализующиеся посредством употребления многочисленных языковых средств, на которые в ходе анализа отобранного материала мы старались обратить особое внимание.

${ }^{23}$ И.Н. С м и р н о в, Ситуации вневременности в современном русском языке, [в:] Функциональный анализ грамматических форм и конструкций, под ред. А.В. Бондарко, Ленинград 1988, с. 35; Э. В и з е, О семантике русских и польских неопределенно-личных и обобщенно-личных предложений, [в:] Problemy składni porównawczej, pod red. M. Bobrana, Rzeszów 1989, с. 40; А. Г а ш, Обобщенно-личные предложения в русских афроризмах, [в:] Kategorie leksykalne i gramatyczne w tekście. Konfrontatywne studia rusycystyczne, pod red. H. Fontańskiego, M. Borek, Katowice 2005, c. 58-65. 
